\title{
OPTIMIZED CONTROL OF ENERGY FLOW IN AN ELECTRIC VEHICLE BASED ON GPS
}

\author{
Matúš Danko*, Branislav Hanko, Peter Drgoňa \\ Mechatronics and Electronics, University of Zilina, Zilina, Slovakia \\ *E-mail of corresponding author: matus.danko@feit.uniza.sk
}

\begin{abstract}
Resume
Presented paper deals with energy flow control of an electric vehicle with multiple energy storages. For efficiency control of energy flow is necessary to know the traction profile of the route. The Global Positioning System is used for observation of the traction profile. The first of the proposed algorithms uses the whole traction profile of a predetermined route, so the control algorithm can determine when the use of energy of the secondary energy storage is useful. The second proposed algorithm uses the GPS to determine the traction profile from routes stored in memory. If the route is not predetermined, or found in the memory of stored routes, the last algorithm controls the energy flow, based on the current of the primary energy storage. For verification of the proposed algorithm for control of the DC/DC converter, motor with inverter was replaced by the programmable power supply and programmable electronic load. The final evaluation shows that the proposed algorithm with the predetermined route saves about 5\% more energy than the basic algorithm based on the battery current.
\end{abstract}

Available online: https://doi.org/10.26552/com.C.2021.1.C7-C14

\section{Article info}

Received 26 May 2020

Accepted 8 June 2020

Online 28 October 2020

\section{Keywords:}

electric vehicle, energy flow, multiple energy storages, GPS

ISSN 1335-4205 (print version)

ISSN 2585-7878 (online version)

\section{Introduction}

Nowadays, electric vehicles and hybrid electric vehicles are more and more common. Although these vehicles are more environmentally friendly and more efficient than vehicles with internal combustion engines, they also have many technical problems, which prevent mass sales and production. One of the main disadvantages is the driving range. For extension of the driving range and increasing vehicle dynamics, multiple energy storages like batteries, supercapacitors, high-speed flywheels and fuel cells are used for powering the electric drive. One or multiple secondary energy storage assist to main energy storage, which leads to decrease of weight and volume of the main energy storage. Energy storages can be divided by their specific power and specific energy. The specific power represents how much power can be delivered per mass unit $(\mathrm{W} / \mathrm{kg})$. The specific energy defines how much energy can be stored per mass unit $(\mathrm{Wh} / \mathrm{kg})$. Batteries are the most common main energy storage because of their high specific energy and relatively high specific power. The supercapacitor is used most often as the secondary energy storage because it has high specific power. The simplest way of connection between the main and secondary energy storage is their parallel connection. The main disadvantage of this type of connection is that voltages of energy storages are the same, so the performance of the secondary energy storage is not fully utilized and control of energy flow is not possible [1-4].
The issue of inefficient energy utilization is the problem of current types of electric vehicles. Furthermore, the style of driving has a significant impact on the energy efficiency of the electric vehicle. In Table 1, the comparison between the presented and real driving range of electric vehicles is shown [3].

Configurations where active control of energy flow is possible, using the DC/DC converter at least for one of the energy storages. The DC/DC converter should be bidirectional to utilize regenerative braking for storing energy [5-6]. In this paper, serial active topology was chosen (Figure 1), because the energy flow is controlled trough one $\mathrm{DC} / \mathrm{DC}$ converter of the secondary energy storage. Thus, the DC/DC converter is active only during the energy control i.e. during the acceleration and during regenerative braking [7-9].

\section{Proposed algorithms}

For the optimal energy flow control of the secondary energy storage, it is necessary to know the traction profile. If the traction profile of the whole track is known or part of the traction profile, the control algorithm can decide when to use the energy of secondary energy storage is useful. Proposed algorithms utilize GPS localization for detection of traction profile. 
Table 1 Claimed and a real range of electric vehicle [3]

\begin{tabular}{|c|c|c|c|c|c|c|}
\hline make & model & claimed range & real range & full charge $€$ & cost per $\mathrm{km} €$ & $\mathrm{~km}$ per $\mathrm{kWh}$ \\
\hline Hyundai & Kona Electric $64 \mathrm{kWh}$ & 467.2 & 414.4 & 10.121 & 0.035 & 5.76 \\
\hline Jaguar & I-Pace & 467.2 & 404.8 & 13.888 & 0.059 & 4.16 \\
\hline Kia & e-Niro 64 kw & 481.6 & 404.8 & 10.226 & 0.047 & 5.6 \\
\hline Tesla & Model S 75D & 486.4 & 326.4 & 11.805 & 0.059 & 3.84 \\
\hline Hyundai & Kona Electric $39 \mathrm{kWh}$ & 310.4 & 252.8 & 6.1659 & 0.035 & 5.76 \\
\hline Renault & Zoe R110 & 297.6 & 233.6 & 7.0551 & 0.047 & 4.64 \\
\hline Nissan & Leaf & 268.8 & 204.8 & 6.318 & 0.047 & 4.48 \\
\hline BMW & i3 $94 \mathrm{Ah}$ & 252.8 & 193.6 & 5.4639 & 0.047 & 4.96 \\
\hline Volkswagen & e-Golf & 230.4 & 187.2 & 4.9959 & 0.047 & 5.28 \\
\hline Hyundai & Ioniq Electric & 278.4 & 187.2 & 4.1769 & 0.035 & 6.24 \\
\hline Smart & Fortwo EQ & 158.4 & 94.4 & 2.8431 & 0.047 & 4.64 \\
\hline
\end{tabular}

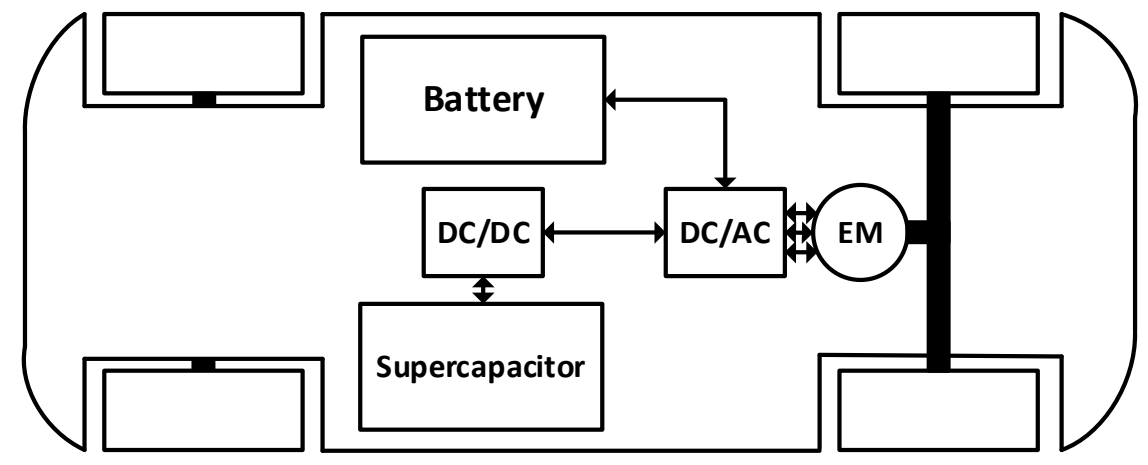

Figure 1 Active serial topology

\subsection{Algorithm with use of the whole traction profile}

In Figure 2 one can see that the first of the proposed algorithms, which uses the whole traction profile has one big disadvantage that the user must set the route on which the electric vehicle will move. On the other hand, a big advantage of this algorithm is that the whole traction profile is known so the algorithm decides on which uphill, the energy of the secondary energy storage will be used, based on the remaining energy of the secondary energy storage.

For example, if the route contains two uphills in a row and remaining energy in the secondary energy storage suffices only for one of uphills, the control algorithm uses energy for the bigger uphill. The same situation occurs at regenerative braking, algorithm decides during which downhill to store energy to the secondary energy storage based on how much energy the secondary energy storage can store.

\subsection{Algorithm with use of a part of the traction profile}

The second algorithm eliminates the disadvantage of the previous algorithm and the user does not have to set the route (Figure 3).
The route is set from memory where the routes, on which the vehicle was moving are stored, based on the GPS localization. At the start of the route, ten coordinates are acquired, which are searched in the routes in memory. Coordinates of singe points are not searched, because of the GPS accuracy, two routes can be searched, each in the opposite direction. The disadvantage is that the whole traction profile of the route is not known and the vehicle can change direction any time, so the energy of the secondary energy storage is used on every uphill. If a vehicle changes direction, coordinates of the new route are searched in the memory. If the new route is not in the memory, the route is saving it in memory until the vehicle stops, which means the end of the route or crossroad, which means the vehicle can continue on the known route.

\subsection{Algorithm based on battery current}

This basic algorithm is used when the route is not searched in the memory or the user does not set the route, so the energy control system cannot decide when to use the energy of the secondary energy storage. Energy usage of the secondary energy storage is based on the maximum specified current of batteries. During the fast acceleration or during the uphill driving, the current exceeds specified current of batteries. If the energy storage has enough energy, the 


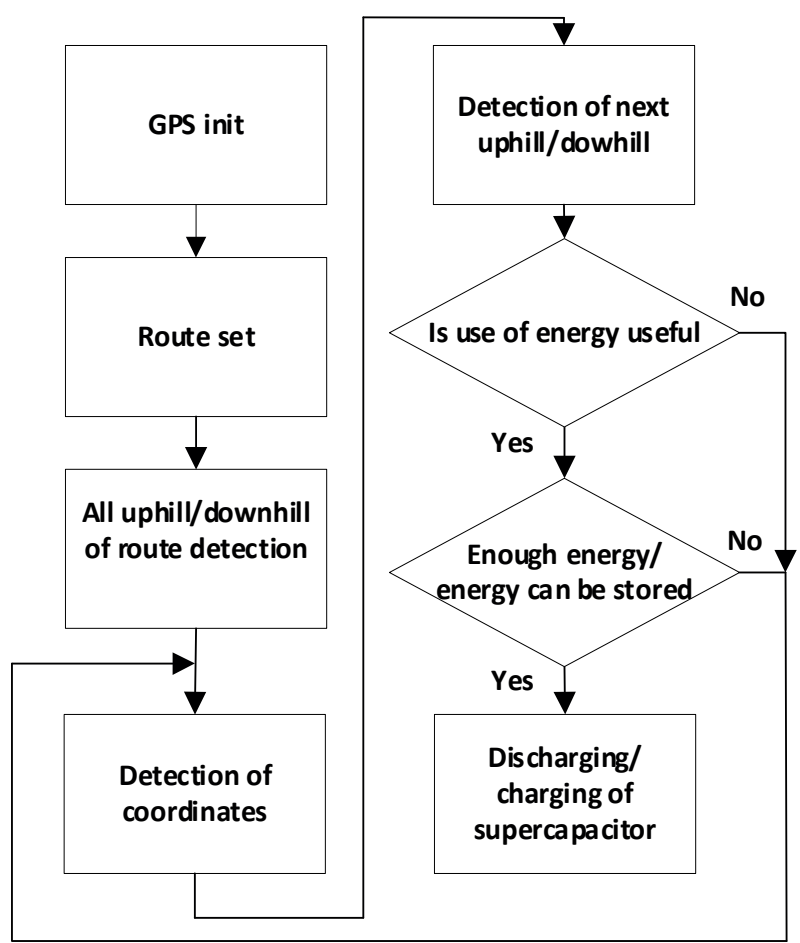

Figure 2 Algorithm with use of the whole traction profile

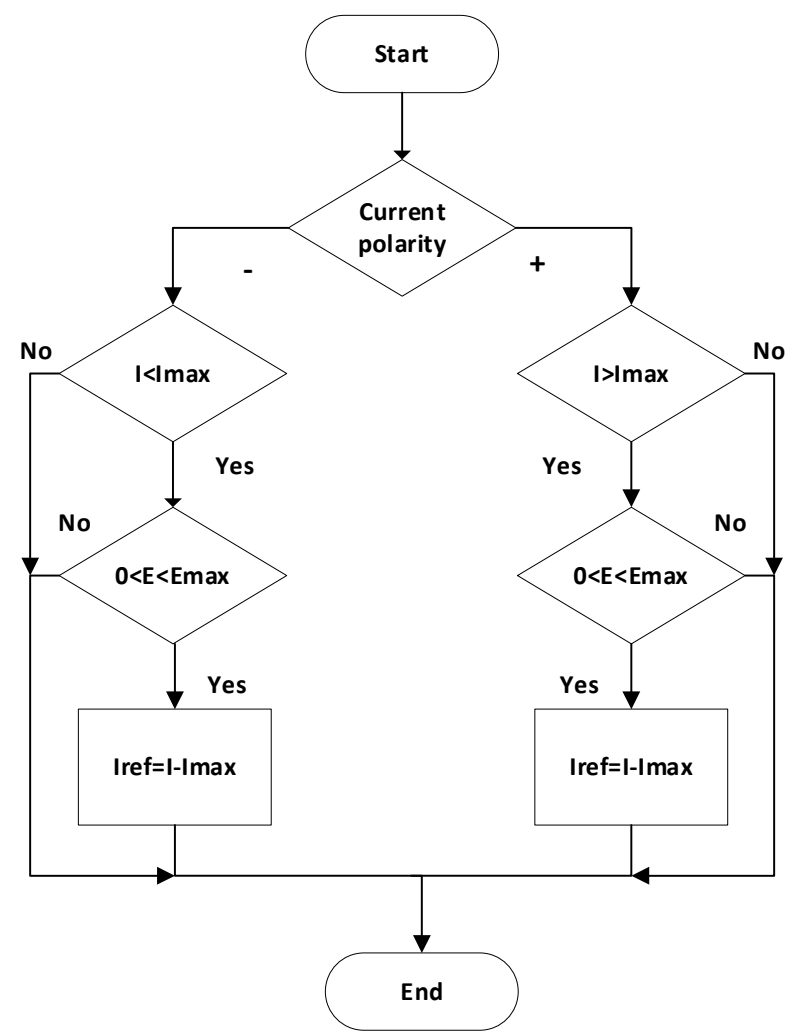

Figure 4 Algorithm based on the battery current

current will be supplied from the secondary energy storage (Figure 4). The same situation occurs during deceleration and the downhill driving. If the current of regenerative braking exceeds the specified current and energy can be stored in the secondary energy storage, the remaining current would flow into the secondary energy storage.

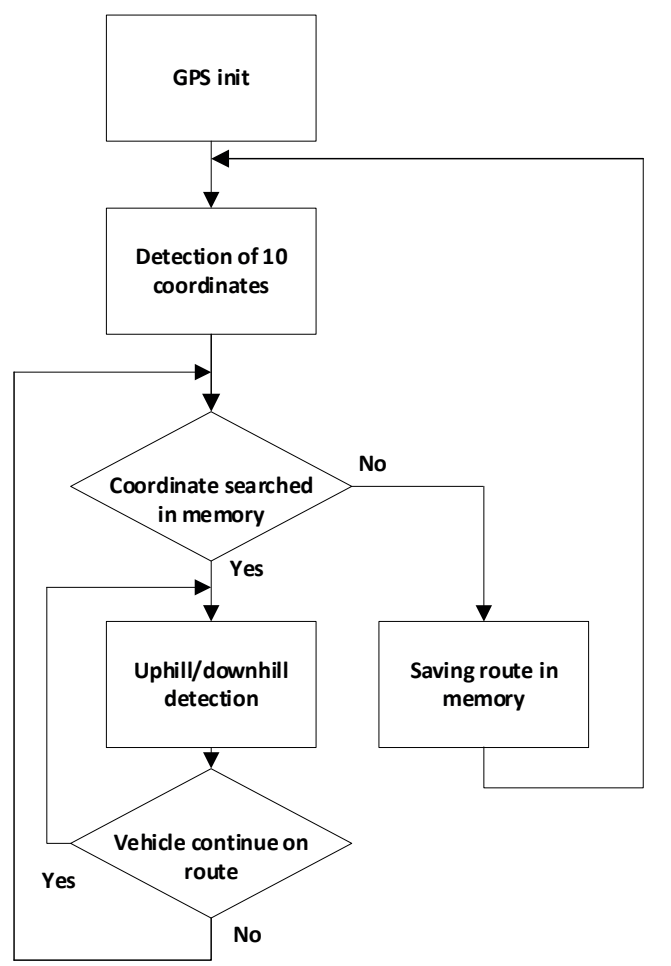

Figure 3 Algorithm with use of a part of the traction profile

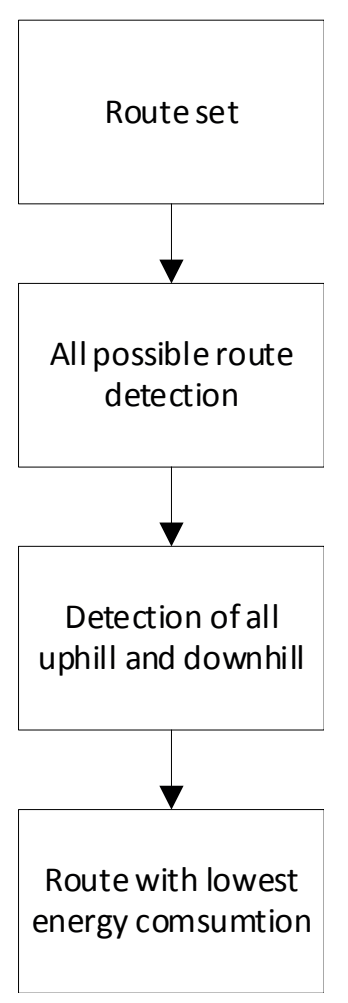

Figure 5 Algorithm for searching for the least energyconsuming route

\subsection{Algorithm for search of the least energy- consuming route}

This algorithm (Figure 5) can be used when energy in the primary energy storage is low. After the user sets destination, the route, which is least energy-consuming, 


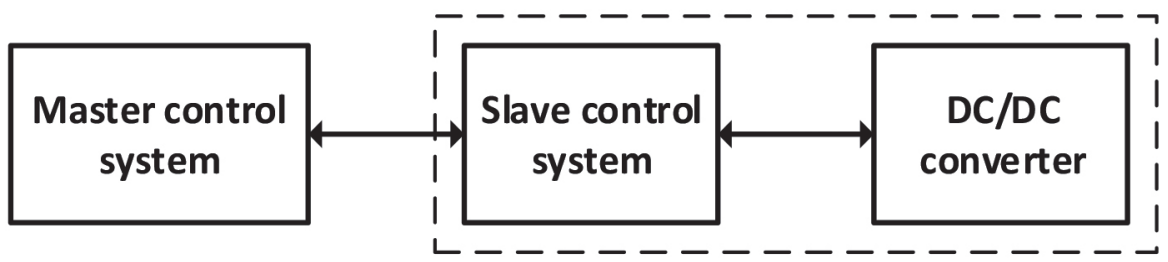

Figure 6 Control system divided into subsystems

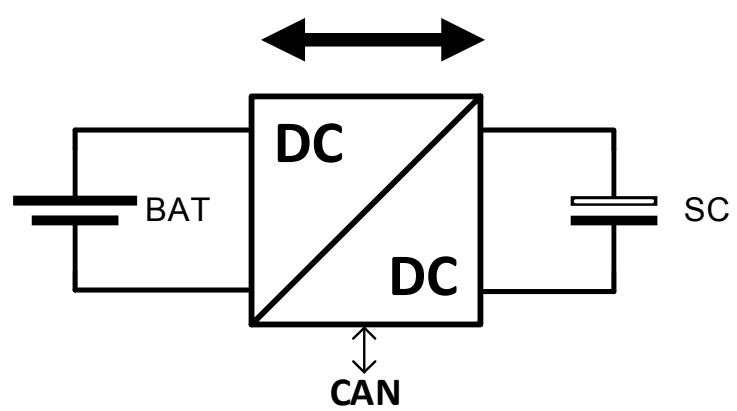

Figure 7 Block diagram of the DC/DC converter connection

that means, the route with the smallest number of the uphills and crossroads will be chosen from the memory.

\section{The DC/DC converter control trough the CAN BUS}

With using of a great amount of electronics in the modern vehicles, the requirement to divide the electronic system of the car to specific sections, by usefulness and reliability, arises. According to the importance of messages, these electronic subsystems have different speeds of the bus. The control system is divided into two subsystems, master and slave control system. The slave subsystem is implemented in the DC/DC converter (Figure 6). The master subsystem communicates with other systems like the infotainment of vehicles to observe the position of the vehicle [10].

\subsection{The CAN BUS}

To save material for cabling of the car and secure communication between sensors, electronic control units and actuators, a communication data bus, called Controller Area Network, abbreviated CAN, by German company Bosh $\mathrm{GmbH}$ at 1980 was proposed. The content of a message is described by an identifier. The Identifier does not indicate the destination of the message, but describes the meaning of the data, so that all the nodes in the network are able to decide by message filtering whether the data is to be acted upon by them or not. Within a CAN network, it is guaranteed that a message is accepted simultaneously either by all the nodes or by no node. Thus, the data consistency is a property of the system achieved by the concepts of multicast and by error handling [11].

Whenever the bus is free, any node may start to transmit a message. If the two or more nodes start transmitting messages at the same time, the bus access conflict is resolved by bit-wise arbitration using the Identifier. The mechanism of arbitration guarantees that neither information nor time is lost. If a Data frame and a Remote frame with the same Identifier are initiated at the same time, the Data frame prevails over the Remote frame. During the arbitration, every transmitter compares the level of the bit transmitted with the level that is monitored on the bus. If those levels are equal, the node may continue to send. When a recessive level is sent, but a dominant level is monitored, the node has lost arbitration and must withdraw without sending any further bits [11-12].

The message transfer is manifested and controlled by four different frame types:

- A Data frame carries data from a transmitter to the receivers;

- A Remote frame is transmitted by a bus node to request the transmission of the Data frame with the same Identifier;

- $\quad$ An Error frame is transmitted by any node on detecting a bus error;

- An Overload frame is used to provide for an extra delay between the preceding and the succeeding Data or Remote frames [11-12].

\subsection{The DC/DC converter with an implemented control subsystem}

The basis of the system is a bidirectional interleaved buck-boost converter, which controls the energy flow between supercapacitors and batteries, as can be seen in Figure 7. The DC/DC converter has three phases with phase shift $120^{\circ}$, which results in a smaller current ripple of energy storages.

The way of energy flow control is shown in Figure 8. If the voltage of the secondary energy storage E2 is half of the voltage of the primary energy storage E1 and duty 


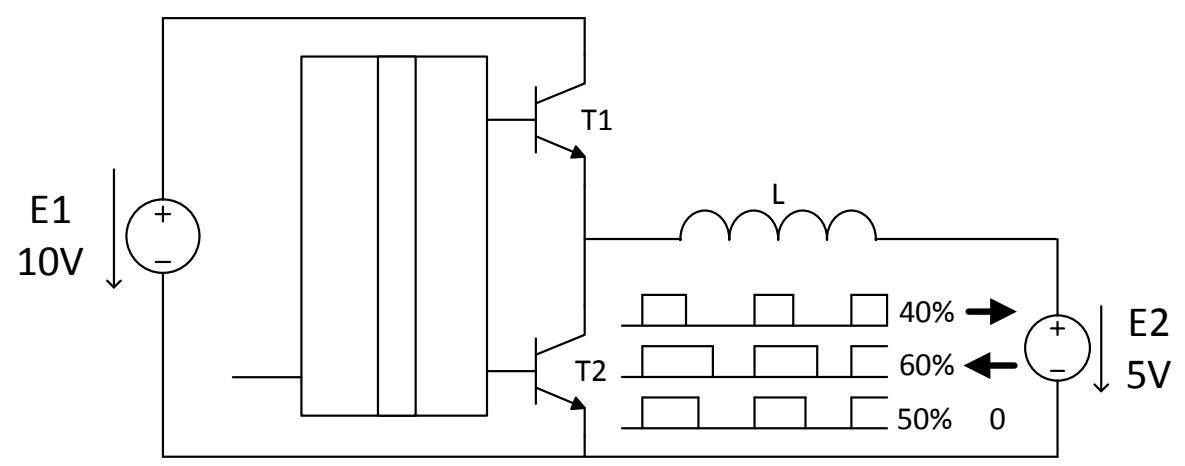

Figure 8 Control of energy flow

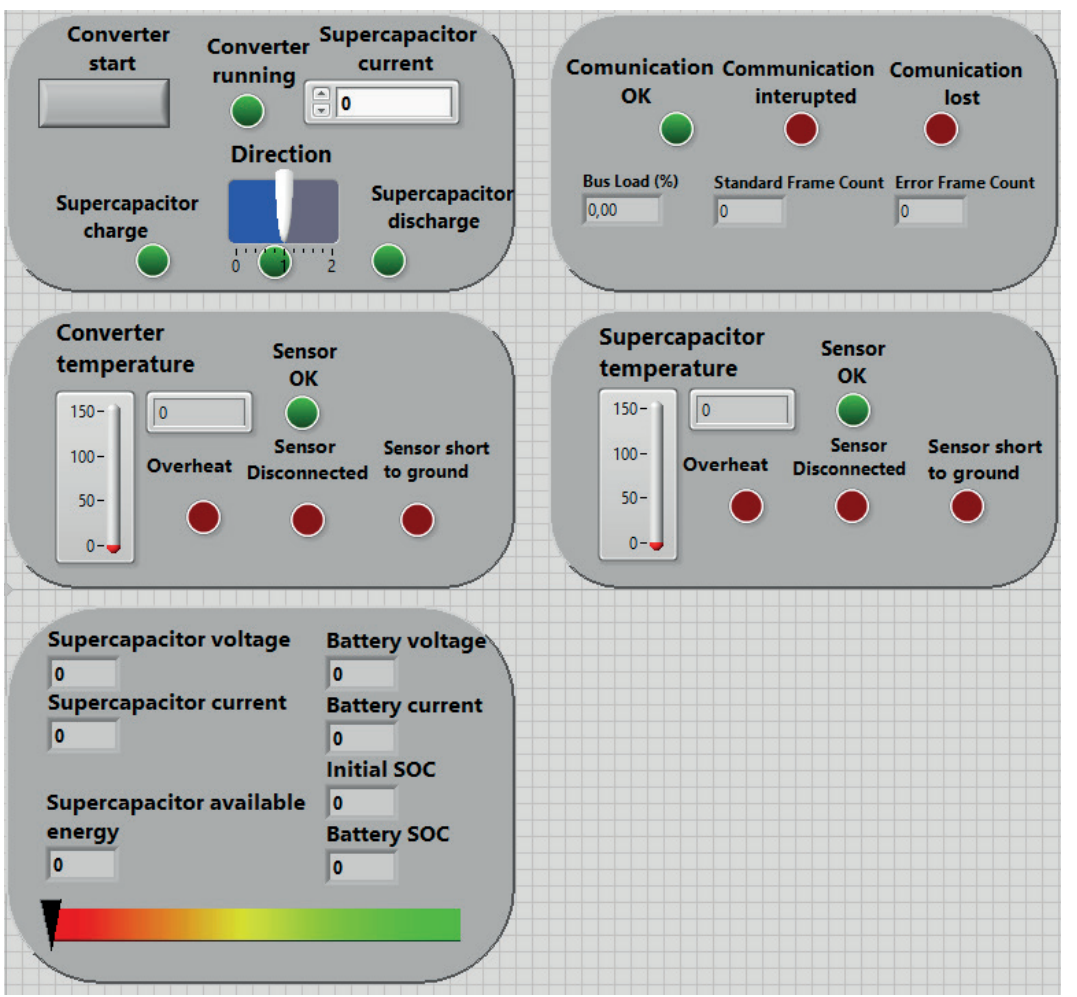

Figure 9 The front panel of the master control system in the LabVIEW

cycle is $50 \%$, there is no transfer of energy. If the duty cycle is greater than $50 \%$, energy from the secondary energy E2 storage will be transferred to the primary energy storage E1 (supercapacitors discharging). If the duty cycle is smaller than 50\%, energy from the primary energy E1 storage will be transferred to the secondary energy storage E2 (supercapacitors charging).

The slave subsystem uses a feed-forward regulator for controlling the converter. This regulator uses a steady-state mathematical model. The current of the DC/DC converter is subsequently tuned by a PI (Proportional Integral) regulator. Action value is limited by next the PI regulators to secure maximal voltage of batteries and supercapacitor, supercapacitor minimal voltage and supercapacitor maximal current. Except for the control of the converter itself, the slave subsystem also provides protection and diagnostics of the converter. The slave subsystem monitors continuity of communication, which must be with period $20 \mathrm{~ms}$ at $500 \mathrm{kbps}$, like communication at powertrain of a real vehicle. If the period is greater, the status of communication is interrupted, while if the communication speed is different, communication status is "communication lost". Both statuses mean that the converter will be turned off. The slave system also monitors the temperature of the converter and supercapacitor. If these temperatures exceed the maximal temperature, the converter will be turned off. The slave subsystem sends the status of converter, temperatures of converter and supercapacitor, battery and supercapacitor voltages, battery and supercapacitor current, to the master subsystem through the CAN-BUS.

\subsection{Master control subsystem}

Themaster control subsystem wasimplementedin visual programing language LabVIEW, since it offers a graphical programming approach that helps to visualize every aspect of applications, including the hardware configuration, measurement data and debugging. The master subsystem sends commands (through the CAN-BUS) for start and stop 


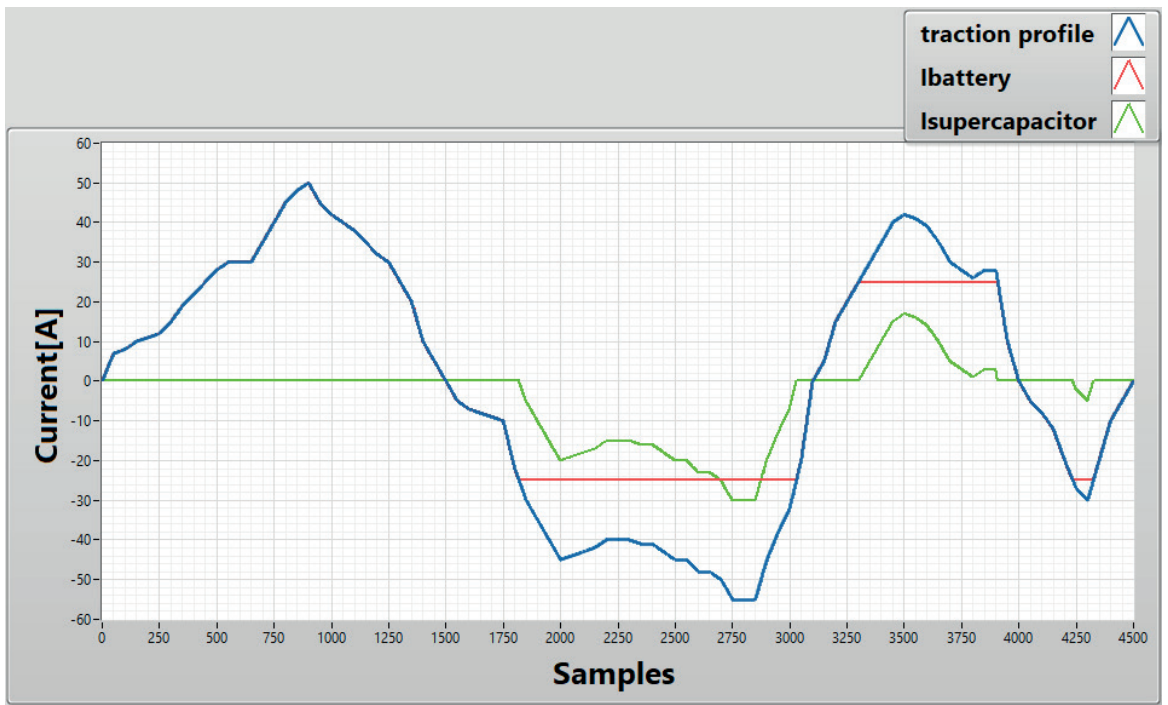

Figure 10 Verification of algorithm based on the battery current

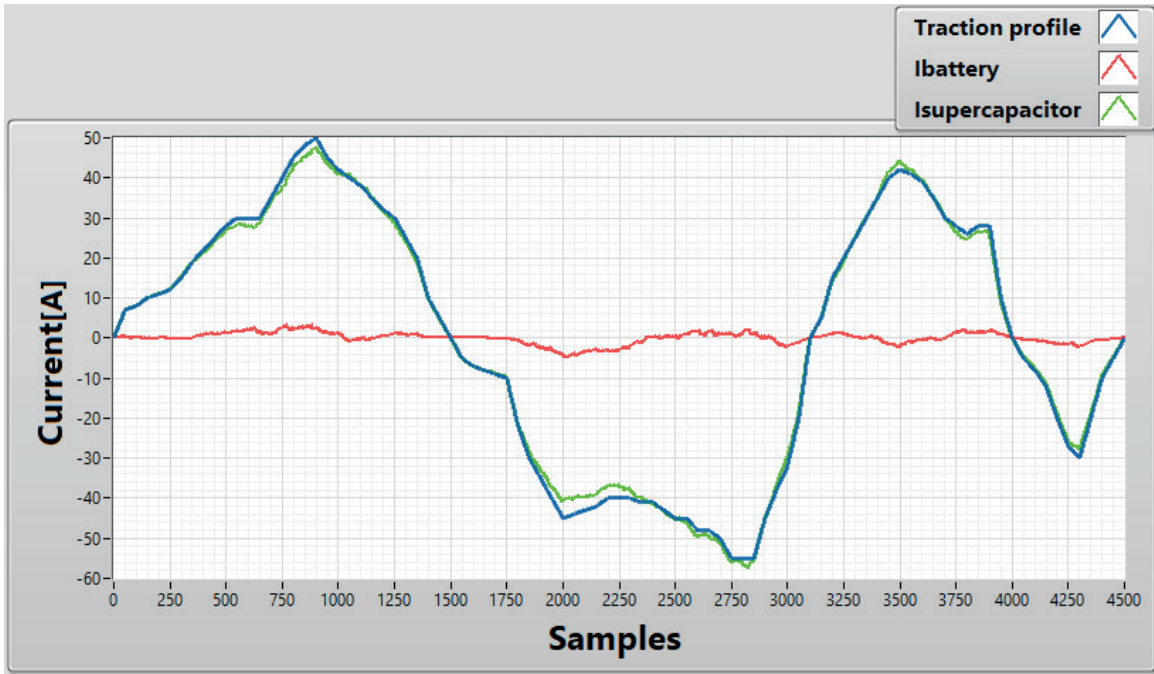

Figure 11 Verification of algorithm using the whole traction profile

of the converter and commands for polarity and size of the current flowing through the DC/DC converter, which are determined from the proposed algorithms. Figure 9 shows the GUI (Graphical User Interface) of master subsystem for manual control of the DC/DC converter. Kvaser Leaf SemiPro was chosen as the CAN bus interface. The Kvaser Leaf SemiPro is a single channel USB interface for the high speed CAN, with the bus speed up to $1000 \mathrm{kbps}$, with up to 15000 messages per second, synchronized with a precision of 25 microseconds. This interface has galvanic isolation, standard DB9 connector and supports both the standard 11-bit identifier and extended 29-bit identifier [13-15].

This control subsystem also estimates a state of charge of batteries that is important for control of power flow. State of Charge (SOC) estimation is realized as a combination of the open-circuit voltage (OCV) method and coulomb counting method. During the start of the program, when a current of batteries is zero, voltage is measured., The SOC is estimated from the lookup table where the dependency OCV on SOC is implemented. Important for this method is that the current must be zero, i.e. this method can be used only when the vehicle does not move. When the vehicle is moving, i.e. the battery current is not zero, the OCV method cannot be used, since the current will be integrated over time, to estimate the state of charge. The energy of the supercapacitor is calculated from its voltage. One of 19 interpreted sentences of the NMEA standard, the \$GPGGA sentence, is used for observation of position and altitude of a vehicle. This sentence contains the time, latitude, longitude, number of satellites and altitude [16-17].

\section{Testing of proposed algorithms}

\subsection{NI cRIO-90822}

For the testing purposes, motor and inverter in the motor mode were simulated with programmable DC electronic load EA-EL 9500-60 and in the generator mode with programmable DC power supply EA-PSI 8060-60. Control was realized with visual programing language LabVIEW, as well. Electronic DC load was connected 
through the USB, using the Modbus protocol, while the programmable power supply was connected by ethernet. Eight series-connected $40 \mathrm{Ah} \mathrm{LiFePO} 4$ traction cells were used as the primary energy storage. Supercapacitor with nominal voltage $16 \mathrm{~V}$ and nominal capacity $500 \mathrm{~F}$ was used as secondary energy storage. The algorithm, which uses part of the traction profile, was implemented for the test purposes as two look up tables (Figure 10). One look-up table is used for the saved traction profile and the second look-up table is used as an actual traction profile. Both look-up tables were saved from the GPS coordinates of the real route. The second implemented algorithm was algorithm based on the maximal battery current (Figure 11)

\section{Conclusions}

This paper has described a system for the energy flow control with multiple energy storages in serial active topology. The LiFePO4 traction cells were used as the primary energy storages and the supercapacitor was used as the secondary energy storage. The control system of a bidirectional DC/DC converter is divided into two subsystems that communicate through the CAN BUS
The slave subsystem is implemented directly into the DC/ DC converter. The master subsystem sends direction and amplitude of current to the slave subsystem through the CAN BUS. Optimization of the energy flow, with proposed algorithms based on GPS, has extended the driving range for up to $5.11 \%$ more than the basic algorithm based on battery current. Extension of the driving range can be greater using a more accurate sensor for altitude detection or for correction of altitude from the GPS because altitude from the GPS is relatively inaccurate. The second way is using the GPS to observe the position and search altitude in the database.

\section{Acknowledgment}

This research was funded by a grant APVV-15-0571: Research of the optimum energy flow control in the electric vehicle system, APVV-17-0218: Investigation of biological tissues with electromagnetic field interaction and its application in the development of new procedures in the design of electrosurgical instruments and ITMS 26210120021- Modernization of research infrastructure in the field of electrical engineering, electrical materials and information and communication technologies.

\section{References}

[1] HUSAIN, I. Electric and hybrid vehicles - design fundamentals. Boca Raton, Florida: CRC PRESS LLC, 2003. ISBN 0-8493- 1466-6, eISBN 0-203-00939-8.

[2] SCHALZ, E. Electrical vehicle design and modeling. In: Electric Vehicles - Modelling and Simulations. SOYLU, S. (ed.). 1. ed. Aalborg University, Denmark: InTech, 2011. ISBN 978-953-307-477-1, p. 1-24.

[3] HULL, R. How far can you go in an alectric car? New test reveals the REAL ranges of models on sale todaz with one faliing 100 MILES SHORT of claims [online] [accessed 2019-11-08]. Available from: https://www.thisismoney.co.uk/ money/cars/article-6337871/New-test-reveals-far-electric-cars-REALLY-travel-charge.html

[4] LINDEN, D., REDDY, T. B. Handbook of batteries. 3. ed. New York: McGraw-Hill, 1995. ISBN 0-07-135978-8.

[5] AL SAKKA, M., VAN MIERLO, J., GUALOUS, H. DC/DC converters for electric vehicle. In: Electric Vehicles - Modelling and Simulations. SOYLU, S. (ed.). 1. ed. Aalborg University, Denmark: InTech, 2011. INTECH, ISBN 978-953-307-477-1, p. 309-332.

[6] DOBRUCKY, B., KASCAK, S., PRAZENICA, M. A novel enhanced connection of AC/AC powertrain for hev - modelling and simulation results. Advances in Electrical and Electronic Engineering [online]. 2018, 16(3), p. 253-260. ISSN 13361376, eISSN 1804-3119. Available from: https://doi.org/10.15598/aeee.v16i3.2874

[7] DOBRUCKY, B., KASCAK, S., PRAZENICA, M.; DRGONA, P., PAVLASEK, P. AC/AC powertrain control under different HEV supply network. In: 12th International Conference on Elektro 2018: proceedings. 2018.

[8] DOBRUCKY, B., KASCAK, S., PRAZENICA, M., JARABICOVA, M., KONARIK, R. Computation and comparison power losses of three- and five-phase converters (VSI) based on datasheet characteristics. In: 23rd International Conference Electronics 2019: proceedings [online. IEEE, 2019. Available from: https://doi.org/10.1109/ELECTRONICS.2019.8765583

[9] KASCAK, S., PRAZENICA, M., JARABICOVA, M., PASKALA, M. Interleaved dc/dc boost converter with coupled inductors. Advances in Electrical and Electronic Engineering [online]. 2018, 16(2), p. 147-154. ISSN 1336-1376, eISSN 1804-3119. Available from: https://doi.org/10.15598/aeee.v16i2.2413

[10] BLAHO, M., ERNEK, M., SUROVCIK, T., MURGAS, T., FODREK, P.. Real-time communication subsystem for CAN bus. International Journal on Communications Antenna and Propagation. 2014, 4(4), p. 108-112. ISSN 2039-5086.

[11] Bosch Controller Area Network (CAN) - Freescale Semiconductor, Inc. Version 2.0 [online] [accessed 2017-02-14]. Available from: https://www.nxp.com/docs/en/reference-manual/BCANPSV2.pdf

[12] Introduction to the Controller Area Network (CAN) - Texas Instrument [online] [accessed 2017-04-05] Available from: http://www.ti.com/lit/an/sloa101b/sloa101b.pdf 
[13] KONIAR, D., HARGAS, L., LONCOVA, Z., DUCHON, F., BENO, P. Machine vision application in animal trajectory tracking. Computer Methods and Programs in Biomedicine [online]. 2016, 127, p. 258-272. ISSN 0169-2607, eISSN 1872-7565. Available from: https://doi.org/ 10.1016/j.cmpb.2015.12.009

[14] SPANIK, P., HARGAS, L., HRIANKA, M., KOZEHUBA, I. Application of virtual instrumentation LabVIEW for power electronic system analysis. In: 12th International Power Electronics and Motion Control Conference EPE-PEMC 2006: proceedings. 2006.

[15] PANCIK, J., BENES, V. Emulation of wheel speed sensors for automotive electronic control unit. In: Industry 4.0: trends in management of intelligent manufacturing systems. KNAPCIKOVA, L., BALOG, M. (eds.). Springer International Publishing, 2019. ISBN 978-3-030-14010-6, eISBN 978-3-030-14011-3

[16] ABDUL-HAK, M., AL-HOLOU, N., MOHAMMAD, U. Predictive intelligent battery management system to enhance the performance of electric vehicle. In: Electric Vehicles - Modelling and Simulations. SOYLU, S. (ed.). 1. ed. Aalborg University, Denmark: InTech, 2011. ISBN 978-953-307-477-1, p. 365-384.

[17] ABU-SHARKH, S., DOERFFEL, D. Rapid test and non-linear model characterization of solid-state lithium-ion batteries. Journal of Power sources [online]. 2004, 130, p. 266-274. ISSN 0378-7753. Available from: https://doi.org/10.1016/j. jpowsour.2003.12.001 